\title{
Research
}

\section{Patient preferences for management of high blood pressure in the UK:}

\author{
a discrete choice experiment
}

\begin{abstract}
Background

With a variety of potentially effective hypertension management options, it is important to determine how patients value different models of care, and the relative importance of factors in their decision-making process.

Aim

To explore patient preferences for the management of hypertension in the UK.

\section{Design and setting}

Online survey of patients who have hypertension in the UK including an unlabelled discrete choice experiment (DCE).

\section{Method}

A DCE was developed to assess patient preferences for the management of hypertension based on four attributes: model of care, frequency of blood pressure (BP) measurement, reduction in 5-year cardiovascular risk, and costs to the NHS. A mixed logit model was used to estimate preferences, willingness-to-pay was modelled, and a scenario analysis was conducted to evaluate the impact of changes in attribute levels on the uptake of different models of care.

\section{Results}

One hundred and sixty-seven participants completed the DCE laged 61.4 years, $45.0 \%$ female, $82.0 \%>5$ years since diagnosis). All four attributes were significant in choice $(P<0.05)$.

Reduction in 5-year cardiovascular risk was the main driver of patient preference as evidenced in the scenario and willingness-to-pay analyses. have high blood pressure (BP), with deprived areas having the highest prevalence.' There have been improvements in recent years, with the population average systolic BP falling by $3 \mathrm{mmHg}$ over the past decade, and the proportion of adults with controlled hypertension increasing from $5 \%$ to $10 \%$ between 2003-2016.' However, managing hypertension remains a significant burden on general practice and accounts for an estimated $12 \%$ of all visit to GPs in England. ${ }^{2}$

Chronic disease management is shifting towards models of care that focus on patient centricity, supporting selfmanagement behaviours and improving care pathways with better integration of healthcare professional teams. ${ }^{3}$ In recent years there has been an increased focus on new models of care for the management of hypertension, often involving the patient more in the process. Studies have investigated using patients' home BP readings to guide treatment, either by bringing them along to consultation or using technology to relay the information (telemonitoring).4,5 Other studies have investigated nurse or pharmacist-led medication titration. ${ }^{6.7}$ Further studies have included self-management whereby patients titrate their own medication according to a pre-arranged plan. ${ }^{8}$
\end{abstract} GP management was significantly preferred over self-management. Patients preferred scenarios with more frequent $\mathrm{BP}$ measurement, and lower costs to the NHS.

\section{Conclusion}

Participants had similar preferences for GP management, pharmacist management, and telehealth, but a negative preference for selfmanagement. When introducing new models of care for hypertension to patients, discussion of the potential benefits in terms of risk reduction should be prioritised to maximise uptake.

\section{Keywords}

general practice, hypertension, patien preference.

\section{INTRODUCTION}

It is likely that one in four adults in the UK

B Fletcher, MPH, DPhil, researcher, Nuffield Department of Primary Care Health Sciences, University of Oxford, and National Perinatal Epidemiology Unit (NPEU), Nuffield Department of Population Health, University of Oxford, Oxford. L Hinton, DPhil, university research lecturer:

R McManus, MA, PhD, FRCGP, FRCP, professor of primary care, Nuffield Department of Primary Care Health Sciences, University of Oxford, Oxford. o Rivero-Arias, MSc, DPhil, associate professor in health economics, National Perinatal Epidemiology Unit (NPEU), Nuffield Department of Population Health, University of Oxford, Oxford.
The National Institute for Health and Care Excellence (NICE), which provides guidelines for use in England, released new draft guidelines for the management of hypertension in early 2019, and discuss the evidence of effectiveness for out-ofoffice BP measurement, and pharmacist management of $\mathrm{BP}^{2}$ The guidelines support home monitoring of $\mathrm{BP}$, where patients are willing and motivated to do so, while stipulating that patients need to know how to measure their BP correctly, and when to contact healthcare professionals if they are not achieving their target BP. With the variety of potentially effective hypertension management options, it is important to determine how patients value different models of care, and the relative importance of factors in their decisionmaking process. For the purposes of this study, a discrete choice experiment (DCE) was used to explore patient preferences for hypertension models of care in the UK: who measures BP, where this occurs, and who leads treatment changes.

There has been an ongoing increase in the publication of health-related DCEs, from approximately 3 per year between 1990-2000, to 45 per year between 20092012, as they are becoming recognised as a useful method for accessing preference for services in health. ${ }^{9}$ A brief description of a DCE is presented in Box 1.

\section{Address for correspondence}

Benjamin Fletcher, Nuffield Department of Primary Care Health Sciences, Radcliffe Observatory Quarter, University of Oxford, Oxford OX2 6GG. UK. Email: benjamin.fletcherAphc.ox.ac.uk

Submitted: 18 March 2019; Editor's response: 24 April 2019; final acceptance: 25 April 2019. (cBritish Journal of General Practice

This is the full-length article (published online 13 Aug 2019) of an abridged version published in print. Cite this version as: Br J Gen Pract 2019; DOI: https://doi.org/10.3399/bjgp19X705101 


\section{How this fits in}

There are a number of effective models of care for the management of hypertension, including GP led, pharmacist led, telehealth, and self-management. Treatment decisions should prioritise effectiveness along with patient preferences through shared decision-making. This study used a discrete choice experiment to investigate patient preferences for hypertension management, and found that patients prioritise reduction in cardiovascular risk. When offering new models of care, it is important to discuss the outcomes in terms of risk and risk reduction, and this may have an impact on the 'buy-in' among patients.

\section{METHOD}

\section{Identifying attributes and levels}

A number of sources of information were used to inform the development and refinement attributes for inclusion in the DCE. Attributes were based on a literature

\section{Box 1. What is a discrete choice experiment?}

A discrete choice experiment (DCE) is a technique for eliciting preferences that provides information about the way individuals value different attributes of health, as well as the potential demand for new programmes, services, or treatments. DCEs are based on the assumption that healthcare interventions/services can be described by their characteristics (or attributes), and that an individual's valuation depends on the levels of the attributes. It is also assumed that individuals behave rationally and make choices that maximise their satisfaction (or utility in economics terminology).

In a DCE participants are presented with a series of questions where they are asked to choose between hypothetical alternatives, each with differing levels of the attributes being tested. In the example below an individual is asked to choose between two chocolate bars ( $A$ and $B$ ), which are described by five attributes lcocoa content, price, size and so on. Each attribute will have a number of potential options or levels.

\section{Which chocolate bar would you prefer?}

\begin{tabular}{lcc}
\hline & Chocolate bar A & Chocolate bar B \\
\hline Cocoa content & $25 \%$ (milk chocolate) & $60 \%$ (dark chocolate) \\
\hline Added ingredients & Almonds, raisins & None \\
\hline Fairtrade? & No & Yes \\
\hline Size & $60 \mathrm{~g}$ & $75 \mathrm{~g}$ \\
\hline Cost & $£ 1.00$ & $£ 1.25$ \\
\hline
\end{tabular}

I would prefer:

- Chocolate bar A

- Chocolate bar B

- Neither

By asking a number of questions in which the levels of the attributes are different, a picture of the strength of preferences for each attribute and level can be built. One is able to investigate the importance that individuals place on different aspects of a product/service, and the extent to which they are willing to make trade-offs between those aspects; for example, the increase/decrease in cost related to the chocolate bar being Fairtrade. When costs are included, DCEs can estimate the willingness-to-pay of particular product/ services/changes in attributes.

The information from a DCE can be used to infer what is important to individuals when making choices in health. It is also possible to estimate the likelihood that individuals would choose a new service and their willingness to pay; vital information when commissioning new services. review, ${ }^{10}$ expert opinion, and interviews with patients with hypertension; 11 participants Iseven females, aged 50-86 years, 73\% $>5$ years since diagnosis) were interviewed between November 2015 and March 2016. Participants were recruited from two general practices in Oxfordshire, one serving a predominantly rural community and the other urban. Interviews were semistructured, followed a topic guide, and were recorded. Transcripts were analysed using a framework approach using NVivo (version 11).

Four attributes were chosen for inclusion in the DCE, and the rationale for inclusion is as described below. Each of the four attributes had four levels and these are shown in Box 2.

Model of care. Model of care for hypertension can be thought of in terms of who measures BP lpatient, nurse, pharmacist, or GPJ and who is responsible for making medication changes in response to the latest BP measurements (GP or nurse/pharmacist/patient according to a prearranged agreement with GP). Varying these two factors resulted in 16 possible combinations. For this experiment it was decided to pick the default option (GP measurement and management) as well as three options that were realistic, actionable by policy, and have already been shown to be effective and acceptable interventions.

Frequency of BP measurement. Currently, it is recommended by NICE that patients with hypertension with well controlled $\mathrm{BP}$ are offered an annual review of their care, and therefore may only have their BP measured for that occasion. ${ }^{11}$ However, $30 \%$ of patients with hypertension currently visit their GP at least three times per year, with one in ten making more than five visits. ${ }^{12}$

Reduction in 5-year cardiovascular risk. Epidemiological evidence at the time of this study suggested that the risk of cardiovascular disease rises with increasing $\mathrm{BP}$ starting at around $115 / 75 \mathrm{mmHg} \cdot{ }^{13} \mathrm{~A}$ large number of clinical trials have shown that lowering systolic BP by $10 \mathrm{mmHg}$ reduces risk of stroke by $35-40 \%$, myocardial infarction by $20-25 \%$, and heart failure by up to $50 \% .^{14}$

Since this study, there have been new reviews of the evidence, with similar findings: ${ }^{15,16}$ for example, in a review and meta-analysis published in 2017, lowering systolic BP by $10 \mathrm{mmHg}$ was associated with $7 \%$ reduction in all-cause mortality, 15\% reduction in cardiovascular mortality, 22\% 


\begin{tabular}{|c|c|}
\hline Attribute & Level \\
\hline Model of care & $\begin{array}{l}\text { GP led - you schedule an appointment during normal clinic hours at } \\
\text { your local general practice. Your BP is measured and any necessary } \\
\text { changes to your medication are made by your GP. } \\
\text { Pharmacist led - you attend a walk-in service (no appointment } \\
\text { required) at your local pharmacy. Your BP is measured by the pharmacist, } \\
\text { and medication changes are made by the pharmacist in accordance with } \\
\text { plan made by you and your GP. } \\
\text { Telehealth - you measure your BP at home using an automated BP } \\
\text { device which automatically transmits the results to your GP. Your GP will } \\
\text { review the measurements you made to make any necessary changes to } \\
\text { your medication. You will not have to schedule any clinic appointments for } \\
\text { your BP as long as it remains controlled. } \\
\text { Self-management - you measure your BP at home using an automated } \\
\text { BP device. You are responsible for making any necessary medication } \\
\text { changes, according to a protocol agreed beforehand with your GP. }\end{array}$ \\
\hline Frequency of measurement & $\begin{array}{l}\text { Every month } \\
\text { Every } 3 \text { months } \\
\text { Every } 6 \text { months } \\
\text { Every } 12 \text { months }\end{array}$ \\
\hline Risk & $\begin{array}{l}\text { By using this service, you will be } 5 \% \text { less likely to have a stroke or heart } \\
\text { attack in the next } 5 \text { years } \\
\text { By using this service, you will be } 10 \% \text { less likely to have a stroke or heart } \\
\text { attack in the next } 5 \text { years } \\
\text { By using this service, you will be } 15 \% \text { less likely to have a stroke or heart } \\
\text { attack in the next } 5 \text { years } \\
\text { By using this service, you will be } 25 \% \text { less likely to have a stroke or heart } \\
\text { attack in the next } 5 \text { years }\end{array}$ \\
\hline Annual cost to the NHS & $\begin{array}{l}£ 50 \\
€ 100 \\
€ 250 \\
£ 500\end{array}$ \\
\hline
\end{tabular}

reduction in major cardiovascular events, $31 \%$ reduction in stroke, and $47 \%$ reduction in heart failure. ${ }^{16}$ Different models of care, with different frequencies of feedback on the results of treatment, and less frequent contact with healthcare providers, have the potential to result in different reductions in cardiovascular disease risk (due to different patterns of medication adherence and medication prescribing).

Costs. It is estimated that diseases caused by hypertension cost the NHS $€ 2$ billion every year. ${ }^{17}$ Cost was framed as cost to the NHS. The cost levels included were based on the costs of healthcare providers' time, as reported in the Unit Costs of Health and Social Care. ${ }^{18}$

\section{Study design and questionnaire}

The DCE presented participants with sets of hypothetical models of care for hypertension that differed according to the levels assigned to the four attributes of interest. Two alternatives ( $A$ and $B$ ) were presented in each choice set. A full factorial design includes all of the possible combinations of the levels and attributes. Given four attributes each with four levels, the full factorial design for one set of choices would be $4^{4}$ (256); and in a pairwise DCE, where two alternatives are presented, the total number of possible pairs would be 32640 (that is, $256 * 255 / 2$ ).

An orthogonal main effects plan with a shifted design was used to create a choice set with 16 choice questions. The final design allowed for the identification of all main effects and had $95.5 \%$ D-efficiency.

The DCE survey was developed using the open source survey tool LimeSurvey (www.limesurvey.org), and administered online. The online survey incorporating the DCE comprised screening questions; choice questions (x16), demographics, and feedback. The final position of each option within each choice (that is, A versus B; B versus $A$ ), and the position of each choice (1-16) were assigned randomly for each participant. 


\section{Table 1. Participant demographics}

\begin{tabular}{|c|c|}
\hline & Participants, $n=167$ \\
\hline Female, $n(\%)$ & $75(45.0)$ \\
\hline Age, years, mean (SD) & $61.4(9.9)$ \\
\hline Age range, years & $25-84$ \\
\hline \multicolumn{2}{|l|}{ Years since diagnosis with hypertension, ${ }^{\mathrm{b}} n(\%)$} \\
\hline$<1$ years & $10(6.1)$ \\
\hline $1-5$ years & 20 (12.3) \\
\hline$>5$ years & 133 (82.0) \\
\hline Measure own BP at home, $n(\%)$ & $86(52.0)$ \\
\hline Number of medications for hypertension, mean (SD) & $1.76(1.06)$ \\
\hline Number of medications for other conditions, mean (SD) & $4.79(3.06)$ \\
\hline \multicolumn{2}{|l|}{ Ethnicity, $n(\%)$} \\
\hline White & 160 (97.0) \\
\hline Mixed/multiple ethnic groups & $1(0.6)$ \\
\hline Asian/Asian British & $3(1.8)$ \\
\hline Black/African/Caribbean/Black British & $1(0.6)$ \\
\hline Other/rather not say & $0(0.0)$ \\
\hline Index of Multiple Deprivation score, mean (SD) & $19.6(17.1)$ \\
\hline \multicolumn{2}{|l|}{ Deprivation from postcode, quintiles $1-5,{ }^{a, b} n(\%)$} \\
\hline 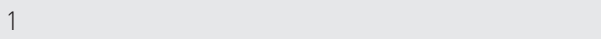 & $44(30.1)$ \\
\hline 2 & 34 (23.3) \\
\hline 3 & 18 (12.3) \\
\hline 4 & $24(16.4)$ \\
\hline 5 & $26(17.8)$ \\
\hline \multicolumn{2}{|l|}{ Highest level of education, ${ }^{\mathrm{b}} n(\%)$} \\
\hline GCSE/O level or equivalent (left school aged 16 years) & $39(24.1)$ \\
\hline A level or equivalent (left school at aged 18 years) & $17(10.5)$ \\
\hline Vocational (NVQ) & $18(11.1)$ \\
\hline University & $79(49.0)$ \\
\hline Other/rather not say & $9(5.5)$ \\
\hline \multicolumn{2}{|l|}{ Employment, ${ }^{\mathrm{b}} n(\%)$} \\
\hline Full-time employment & $36(22.2)$ \\
\hline Part-time employment & $21(12.9)$ \\
\hline Homemaker looking after family & $3(1.9)$ \\
\hline Student in full-time education & $0(0.0)$ \\
\hline Retired & $99(61.1)$ \\
\hline Unemployed & $3(1.9)$ \\
\hline \multicolumn{2}{|c|}{$\begin{array}{l}{ }^{a} \text { According to Multiple Deprivation Score, } 1 \text { is least deprived. }{ }^{b} \text { Demographic questions were not mandatory and } \\
\text { there were some missing data where responders chose not to answer. } B P=\text { blood pressure. } N V Q=\text { National } \\
\text { Vocational Qualification. SD = standard deviation. }\end{array}$} \\
\hline
\end{tabular}

\section{Sample size consideration}

Sample size was calculated using the 'rule of thumb' method proposed by Johnson and Orme for DCEs without prior information, which estimated that at least 100 participants would be required. ${ }^{19,20}$ Simulation was conducted to understand whether the parameters of the models were estimable for different sample sizes, and confirmed the experimental design was robust with sample size $n>100$.

\section{Participants and data collection}

A database of patients who registered interest in taking part in research was used to recruit participants. 'Research for the
Future' is an NHS-supported campaign to encourage people to take part in health research opportunities and includes Help BEAT Diabetes, Help BEAT Respiratory Disease, and Help BEAT Heart Disease. An email was sent to all registered patients, and adults with a self-reported diagnosis of hypertension were invited to take part.

\section{Data analysis}

Participant demographics were summarised using descriptive statistics.

A full description of statistical methods is available from the author on request. DCE data were analysed using a random parameter mixed logit model. These results were used to conduct a post-estimation scenario analysis to investigate what the predicted uptake of different models of care would be if all were available to patients (that is, what was the value that patients place on each model of care). The predicted probabilities that patients would choose each model of care was estimated assuming participants had access to all four, and all else being equal (in this case all other attributes set to the baseline category). Also assessed was the impact that single level changes have on overall predicted uptake lchange in the predicted uptake if the frequency of BP measurements at the GP practice increased from monthly to three times a month, was estimated). ${ }^{21}$ The impact of level changes in overall predicted uptake for the three attributes other than model of care in the DCE was evaluated, and these results are presented using the absolute change in predicted uptake from baseline and associated 95\% confidence intervals (Cls). All analyses were conducted using Stata (version14).

\section{RESULTS}

\section{Participant characteristics}

An invitation to take part was emailed to 2761 individuals, and between 3-20 June 2016, 263 people opened the link to the questionnaire. Of those who opened the link, 42 (16\%) were not eligible (that is, did not have hypertension, or were $<18$ years old). One hundred and sixty-seven of the 221 eligible participants who opened the link completed the questionnaire $(76 \%)$. Fiftyfour $(24 \%)$ completed at least one choice question, but did not finish the questionnaire, and were excluded from the analysis.

Responder characteristics are shown in Table 1. Mean age was 61.4 years and $45.0 \%$ were women. The majority $(82.0 \%)$ had a diagnosis of hypertension for $>5$ years, and took an average of two BP medications. The majority of the responders $(n=160)$ 
Table 2. Parameter coefficients from the random parameter mixed logit model

\begin{tabular}{|c|c|c|c|}
\hline \multicolumn{4}{|c|}{ Parameters } \\
\hline Variable & Coefficient & $95 \% \mathrm{Cl}$ & $P$-value \\
\hline Model of care (reference category GP) & [0] & & \\
\hline Pharmacist & -0.094 & -0.291 to 0.104 & 0.353 \\
\hline Telehealth & -0.191 & -0.421 to 0.039 & 0.103 \\
\hline Self-management & -0.306 & -0.597 to -0.015 & 0.039 \\
\hline Frequency of BP measurement (monthly) & [0] & & \\
\hline Every 3 months & -0.079 & -0.265 to 0.107 & 0.406 \\
\hline Every 6 months & -0.231 & -0.440 to -0.022 & 0.030 \\
\hline Annually & -0.837 & -1.017 to -0.658 & $<0.001$ \\
\hline Reduction in 5-year CV risk (5\%) & [0] & & \\
\hline $10 \%$ & 1.083 & 0.888 to 1.278 & $<0.001$ \\
\hline $15 \%$ & 1.099 & 0.879 to 1.319 & $<0.001$ \\
\hline $25 \%$ & 1.863 & 1.599 to 2.128 & $<0.001$ \\
\hline Cost to NHS, $€$ & -6.167 & -6.424 to -5.911 & $<0.001$ \\
\hline \multicolumn{4}{|c|}{ Standard deviations } \\
\hline Variable & Coefficient & SE & $P$-value \\
\hline Model of care (reference category GP) & [0] & & \\
\hline Pharmacist & 0.684 & 0.119 & $<0.001$ \\
\hline Telehealth & 0.692 & 0.149 & $<0.001$ \\
\hline Self-management & 1.587 & 0.159 & $<0.001$ \\
\hline Frequency of BP measurement (monthly) & [0] & & \\
\hline Every 3 months & 0.021 & 0.107 & 0.848 \\
\hline Every 6 months & 0.071 & 0.116 & 0.538 \\
\hline Annually & 0.076 & 0.151 & 0.615 \\
\hline Reduction in 5-year CV risk (5\%) & [0] & & \\
\hline $10 \%$ & 0.106 & 0.129 & 0.410 \\
\hline $15 \%$ & 0.091 & 0.144 & 0.526 \\
\hline $25 \%$ & 1.037 & 0.135 & $<0.001$ \\
\hline Cost to NHS, $\mathrm{E}$ & 0.910 & 0.094 & $<0.001$ \\
\hline \multicolumn{4}{|c|}{ Goodness of fit } \\
\hline Number of observations & 5344 & & \\
\hline Number of choices & 2672 & & \\
\hline Log likelihood & -1432 & & \\
\hline
\end{tabular}

described themselves as white (97.0\%), over half were retired (61.1\%), and around half reported university as their highest level of education $(49.0 \%)$. Half $(52.0 \%)$ of responders reported measuring their BP at home. According to the Index of Multiple Deprivation score, participants lived in areas evenly spread across quintiles.

\section{Patient preferences for hypertension model of care}

Results from the random parameter mixed logit model are presented in Table 2. All attributes have at least one significant difference between levels indicating that all played an important part in decisionmaking. The coefficient for cost was negative and significant indicating that responders preferred scenarios that cost less to the NHS. Within model of care, all coefficients were negative, indicating that GP management (the reference categoryl was preferred to all other options, although only the coefficient for selfmanagement was statistically significant. For frequency of BP measurement, the trend was towards preference for more frequent BP measurement, with 6-monthly and annual BP measurement having significant negative coefficients. Reduction in cardiovascular risk was a significant driver of preferences, with participants preferring increased reduction in 5-year cardiovascular risk. All of the coefficients were positive and statistically significant.

Statistically significant standard deviations were observed for all of the levels in model of care, for $25 \%$ reduction in cardiovascular 
Table 3. Willingness to pay

\begin{tabular}{|c|c|c|c|}
\hline \multicolumn{4}{|c|}{ Parameters } \\
\hline Variable & Coefficient & $95 \% \mathrm{Cl}$ & $P$-value \\
\hline Model of care (reference category GP) & [0] & & \\
\hline Pharmacist & 20.19 & -52.24 to 92.62 & 0.585 \\
\hline Telehealth & -48.02 & -126.08 to 30.04 & 0.228 \\
\hline Self-management & -70.52 & -170.95 to 29.91 & 0.169 \\
\hline Frequency of BP measurement (monthly) & [0] & & \\
\hline Every 3 months & -4.90 & -74.79 to 65.00 & 0.891 \\
\hline Every 6 months & -67.48 & -145.79 to 10.44 & 0.090 \\
\hline Annually & -247.90 & -318.71 to -177.08 & $<0.001$ \\
\hline Reduction in 5-year CV risk (5\%) & [0] & & \\
\hline $10 \%$ & 374.74 & 297.80 to 451.69 & $<0.001$ \\
\hline $15 \%$ & 398.98 & 308.43 to 489.52 & $<0.001$ \\
\hline $25 \%$ & 673.45 & 561.70 to 785.20 & $<0.001$ \\
\hline Cost to NHS, $€$ & -5.87 & -6.05 to -5.69 & $<0.001$ \\
\hline \multicolumn{4}{|c|}{ Standard deviations } \\
\hline Variable & Coefficient & SE & $\boldsymbol{P}$-value \\
\hline Model of care (reference category GP) & [0] & & \\
\hline Pharmacist & 219.68 & 38.18 & $<0.001$ \\
\hline Telehealth & 71.99 & 46.73 & 0.123 \\
\hline Self-management & 514.25 & 60.40 & 0.000 \\
\hline Frequency of BP measurement (monthly) & [0] & & \\
\hline Every 3 months & 8.46 & 31.18 & 0.791 \\
\hline Every 6 months & 8.63 & 30.73 & 0.779 \\
\hline Annually & 43.39 & 32.02 & 0.175 \\
\hline Reduction in 5-year CV risk (5\%) & [0] & & \\
\hline $10 \%$ & 62.04 & 35.84 & 0.083 \\
\hline $15 \%$ & 4.65 & 31.77 & 0.884 \\
\hline $25 \%$ & 278.10 & 41.87 & $<0.001$ \\
\hline Cost to NHS, $€$ & 0.665 & 0.106 & $<0.001$ \\
\hline \multicolumn{4}{|c|}{ Goodness of fit } \\
\hline Number of observations & 5344 & & \\
\hline Number of choices & 2672 & & \\
\hline Log likelihood & -1451 & & \\
\hline
\end{tabular}

disease risk, and for the cost attribute. This indicated that for these attributes/ levels there was considerable random (unexplained) variation across participants. Exploratory analyses indicated that age may account for some of the heterogeneity within model of care (that is, younger versus older having different preferences); however, results were inconclusive (further information is available from the author on request).

Trade-offs between attributes were calculated in terms of cost, to determine how much participants were willing to pay, and results are presented in Table 3. All else being equal, participants were willing to pay (that is the cost to the NHS) $€ 374.74$, $€ 398.98$, and $€ 673.45$ for $10 \%, 15 \%$, and $25 \%$ reduction in 5-year cardiovascular disease risk, respectively. Willingness to pay for annual BP measurement was - $€ 247.90$ reflecting the negative preference for this attribute level (conversely this can be interpreted as participants being willing to pay $€ 247.90$ for monthly BP measurement over annual measurement).

\section{Post-estimation scenario analysis}

The impact of single level changes to attributes (all else being equal) on uptake of different models of care were investigated, and these results are shown in Table 4. For example, changing the reduction in 5 -year cardiovascular disease risk from $5 \%$ to $10 \%$ increased uptake of GP management by $21.5 \%(95 \% \mathrm{Cl}=11.5$ to 31.6). Similarly, changing the reduction in 5-year cardiovascular disease risk by the same level for self-management was associated with an increase in uptake of 


\section{Table 4. Comparison of change in predicted probabilities for each model of care in response to changes in}

selected attributes

\begin{tabular}{|c|c|c|c|c|c|}
\hline & & GP & Pharmacist & Telehealth & Self-management \\
\hline \multicolumn{2}{|c|}{ Baseline uptake, $\%(95 \% \mathrm{Cl})^{\mathrm{a}}$} & 25.7 (22.0 to 28.3 ) & 24.8 (21.1 to 27.7) & $23.3(19.2$ to 26.4$)$ & 26.2 (23.4 to 32.8 ) \\
\hline \multicolumn{6}{|c|}{ Change in probability from baseline, $\%(95 \% \mathrm{Cl})^{b}$} \\
\hline \multicolumn{6}{|c|}{ Frequency of BP measurement } \\
\hline & Monthly to every 3 months & $-2.5(-11.7$ to 6.7$)$ & $-1.5(-10.7$ to 7.6$)$ & $-2.6(-11.5$ to 6.3$)$ & $0.0(-9.4$ to 9.5$)$ \\
\hline & Monthly to every 6 months & $-4.7(-13.7$ to 4.4$)$ & $-4.4(-13.4$ to 4.5$)$ & $-3.9(-12.6$ to 4.9$)$ & $-1.8(-11.1$ to 7.6$)$ \\
\hline \multicolumn{6}{|c|}{ Reduction in 5-year cardiovascular risk } \\
\hline & $5 \%$ to $10 \%$ & 21.5 (11.5 to 31.6$)$ & 20.9 (10.9 to 30.9) & $20.2(10.4$ to 30.1$)$ & 18.9 (8.8 to 28.9) \\
\hline & $5 \%$ to $15 \%$ & 22.0 (11.9 to 32.0$)$ & $21.9(11.9$ to 31.9$)$ & 19.9 (10.0 to 29.8$)$ & 17.3 (7.3 to 27.4 ) \\
\hline & $5 \%$ to $25 \%$ & $34.1(24.2$ to 44.1$)$ & 35.1 (25.1 to 45.0$)$ & $34.2(24.3$ to 44.1$)$ & 32.1 (22.1 to 42.1) \\
\hline \multicolumn{6}{|c|}{ Cost to NHS } \\
\hline & $€ 50$ to $€ 100$ & $-2.9(-12.1$ to 6.3$)$ & $-1.1(-10.3$ to 8.1$)$ & $-2.8(-11.7$ to 6.0$)$ & $-0.3(-9.7$ to 9.1$)$ \\
\hline & $£ 50$ to $€ 150$ & $-6.9(-15.8$ to 2.0$)$ & $-8.7(-17.3$ to 0.1$)$ & $-7.0(-15.5$ to 1.5$)$ & $-5.7(-14.7$ to 3.4$)$ \\
\hline
\end{tabular}

${ }^{a}$ Baseline uptake represents the predicted probabilities that participants would choose each model of care assuming participants had access to all four, all else being equal.

${ }^{b}$ Refers to change from baseline uptake and represents absolute change in proportions. $B P=b l o o d$ pressure.

$18.9 \%(95 \% \mathrm{Cl}=8.8$ to 28.9$)$. Increases in the frequency of BP measurement were associated with increases in predicted uptake. Increases in cost were associated with decreases in predicted uptakes.

\section{DISCUSSION}

\section{Summary}

This study appears to be the first time a DCE has been conducted to investigate patient preferences for the management of hypertension. All attributes included in the experiment had at least one significant level in the mixed logit analysis indicating that they were all important with regards to patient preferences. There was no evidence of a difference in patient preferences for GP management, pharmacist management, or telehealth, while there was evidence that participants preferred GP management over self-management. Patients preferred scenarios that had greater reduction in cardiovascular risk, more frequent BP monitoring, and lower costs. Risk was the most important driver of choice as evidenced by both the scenario analysis and the marginal willingness-to-pay analysis.

\section{Strengths and limitations}

This was an experimental study and participant choices may not represent how individuals behave in real-world situations. As three of the models of care were not available routinely to patients in the UK, an experimental approach was the only way of determining how patients may make choices about the management of hypertension. The GP-led care model may also not represent the 'usual care' option for some, as care is often provided by practice nurses in England. As mentioned previously, the direction of effects for risk (choosing greater risk reduction) and cost (choosing lower cost), combined with the fact that all four attributes were important in decision-making, provide evidence that participants engaged with the choice tasks and that the choices were appropriate. To validate the findings requires observation of actual choices, and until all of the options included here are routinely available, this will be difficult.

A strength of DCEs in general is that they present information to participants that resembles real-world decisions; that is, to say that decisions are based on a number of different, and sometimes competing, priorities. This analysis represents average preferences across participants, and there was evidence of heterogeneity, particularly in the model of care attribute. Therefore, there is a need to recognise that not all patients want the same thing, and further research should focus on investigating groups of patients with similar preferences.

Care should be taken in interpreting the results beyond the included sample. The final sample was well educated and almost all participants described themselves as white. This reflects the challenge across research studies in recruiting participants from minority groups. Future studies should 
target minority groups, as these groups often have the worse cardiovascular outcomes.

\section{Comparison with existing literature}

Previous research into self-monitoring, telehealth, and new models of care has shown that patients are willing to engage, and that these can be clinically effective. This study provides evidence that patients in the general population are willing to consider change. ${ }^{10,22,23}$ Based on research evidence, some of these new ways of managing hypertension are being introduced into usual care. In the UK the majority of patients are now likely to measure their own BP at home and to discuss this with their GPs, and GPs are more comfortable using these measures to guide treatment. ${ }^{24}$ Since the inception of this study, NHS England has invested significantly in a pilot of practicebased pharmacists. ${ }^{25}$ This study included community pharmacy as an option, as interviews showed that patients found visits to the pharmacy more convenient Imore options locally, often closer to home, and able to visit without the need to make an appointment). Management of hypertension is one option where practicebased pharmacists could be engaged.

However, it is worth noting that participants in this survey had a negative preference for self-management. It might be the case that patients are willing to become more involved in their care up to a point, but are wary of too much change. This preference may shift over time as patients become more used to being more involved in their care. Patients in trials of self-management have reported positive experiences; however, may have been asked to reflect on their experience, rather than their concerns before beginning.

\section{Implications for practice}

Participants prioritised services that reduced their cardiovascular risk. Scenario analysis showed that when the outcome changed from lowest to highest risk reduction category, the likelihood that participants would choose a model of care doubled. When offering new models of care, it is important to discuss the outcomes in terms of risk and risk reduction, and this may have an impact on the 'buy-in' among patients. In a policy environment that promotes patient choice, DCEs are a promising method for investigating preferences, and modelling future demand when commissioning new services.

This study investigated patient preferences for the management of hypertension and found a number of factors that were important. Participants had similar preferences for GP management, pharmacist management, and telehealth, but a negative preference for selfmanagement. When introducing new models of care for hypertension to patients, discussion of the potential benefits in terms of risk reduction should be prioritised to maximise uptake.
Ethical approval for the patient interviews was granted by Health and Social Care Research Ethics Committee A on 01/10/2015 (reference number: 15/NI/0199). Ethical approval for administration of the online questionnaire DCE was granted by the University of Oxford Medical Sciences Inter-Divisional Research Ethics Committee on 12/05/2016 (reference number: R5623/ RE001).

\section{Competing interests}

The authors declare no competing interests.

\section{Acknowledgements}

The authors would like to thank the participants in this study, and Research for the Future for their help in contacting potential participants.

\section{Open access}

This article is Open Access: CC BY-NC 4.0 licence (http://creativecommons.org/ licences/by-nc/4.0/).

\section{Discuss this article}

Contribute and read comments about this article: bjgp.org/letters 


\section{REFERENCES}

1. NHS Digital. Health Survey for England. 2017. https://digital.nhs.uk/data-andinformation/publications/statistical/health-survey-for-england/2017 laccessed 1 Aug 2019]

2. National Institute for Health and Care Excellence. Guideline. Hypertension in adults: diagnosis and management. Draft for consultation, March 2019. https:// mww.nice.org.uk/guidance/gid-ng10054/documents/draft-guideline laccessed 1 Aug 2019).

3. Bodenheimer $\mathrm{T}$, Wagner $\mathrm{EH}$, Grumbach $\mathrm{K}$. Improving primary care for patients with chronic illness. JAMA 2002; 288(14): 1775-1779.

4. Uhlig K, Patel K, Ip S, et al. Self-measured blood pressure monitoring in the management of hypertension: a systematic review and meta-analysis. Ann Intern Med 2013; 159(3): 185-194.

5. Omboni S, Gazzola T, Carabelli G, Parati G. Clinical usefulness and cost effectiveness of home blood pressure telemonitoring: meta-analysis of randomized controlled studies. J Hypertens 2013; 31(3): 455-467; discussion 67-68.

6. Clark CE, Smith LFP, Taylor RS, Campbell JL. Nurse led interventions to improve control of blood pressure in people with hypertension: Systematic review and meta-analysis. BMJ 2010; 341: c3995

7. Santschi V, Chiolero A, Colosimo AL, et al. Improving blood pressure control through pharmacist interventions: a meta-analysis of randomized controlled trials. J Am Heart Assoc 2014; 3(2): e000718.

8. McManus RJ, Mant J, Franssen M, et al. Efficacy of self-monitored blood pressure, with or without telemonitoring, for titration of antihypertensive medication (TASMINH4): an unmasked randomised controlled trial. Lancet 2018; 391(10124): 949-959

9. Clark MD, Determann D, Petrou S, et al. Discrete choice experiments in health economics: a review of the literature. Pharmacoeconomics 2014; 32(9): 883-902.

10. Fletcher BR, Hinton L, Hartmann-Boyce J, et al. Self-monitoring blood pressure in hypertension, patient and provider perspectives: A systematic review and thematic synthesis. Patient Educ Couns 2016; 99(2): 210-219.

11. National Institute for Health and Care Excellence. Hypertension in adults: diagnosis and management. Clinical guideline [CG127]. 2011. https://www.nice. org.uk/guidance/cg127 laccessed 1 Aug 2019).

12. National Services Scotland. Practice Team Information (PTI) annual update (2012/2013). National Statistics Publication for Scotland 2013. https://www. isdscotland.org/Health-Topics/General-Practice/Publications/2013-10-29/201310-29-PTI-Report.pdf (accessed 1 Aug 2019).
13. Lewington S, Clarke R, Qizilbash N, et al. Age-specific relevance of usual blood pressure to vascular mortality: a meta-analysis of individual data for one million adults in 61 prospective studies. Lancet 2002; 360(9349): 1903-1913.

14. Turnbull F. Effects of different blood-pressure-lowering regimens on major cardiovascular events: results of prospectively-designed overviews of randomised trials. Lancet 2003; 362(9395): 1527-1535.

15. Brunstrom M, Carlberg B. Association of blood pressure lowering with mortality and cardiovascular disease across blood pressure levels: a systematic review and meta-analysis. JAMA Intern Med 2018; 178(1): 28-36.

16. Bundy JD, Li C, Stuchlik P, et al. Systolic blood pressure reduction and risk of cardiovascular disease and mortality: a systematic review and network metaanalysis. JAMA Cardiol 2017; 2(7): 775-781.

17. Public Health England. New figures show high blood pressure costs NHS billions each year. https://uww.gov.uk/government/news/new-figures-showhigh-blood-pressure-costs-nhs-billions-each-year laccessed 1 Aug 2019).

18. Curtis L, Burns A. Unit costs of health and social care 2015. 2015. https://uww. pssru.ac.uk/project-pages/unit-costs/unit-costs-2015/ laccessed 1 Aug 2019).

19. de Bekker-Grob EW, Donkers B, Jonker MF, Stolk EA. Sample size requirements for discrete-choice experiments in healthcare: a practical guide. Patient 2015; 8(5): 373-384

20. Johnson R, Orme B. Getting the most from CBC. Sawtooth Software Research Paper Series 2003. https://www.sawtoothsoftware.com/download/techpap/ cbcmost.pdf laccessed 1 Aug 2019).

21. Lancsar E, Fiebig DG, Hole AR. Discrete choice experiments: a guide to model specification, estimation and software. Pharmacoeconomics 2017; 35(7): 697-716.

22. Hanley J, Pinnock H, Paterson M, McKinstry B. Implementing telemonitoring in primary care: learning from a large qualitative dataset gathered during a series of studies. BMC Fam Pract 2018; 19(1): 118.

23. Carter BL, Bosworth HB, Green BB. The hypertension team: the role of the pharmacist, nurse, and teamwork in hypertension therapy. J Clin Hypertens (Greenwich) 2012; 14(1): 51-65.

24. Fletcher BR, Hinton L, Bray EP, et al. Self-monitoring blood pressure in patients with hypertension: an internet-based survey of UK GPs. Br J Gen Pract 2016; DOI: https://doi.org/10.3399/bjgp16X687037.

25. NHS England. Clinical pharmacists in general practice. https://mww.england nhs.uk/gp/gpfv/workforce/building-the-general-practice-workforce/cp-gp/ laccessed 1 Aug 2018). 